\title{
Analysis of Entrepreneurial Leadership Skills and Sustainable Employee Productivity of MSMEs
}

\author{
Josephine Diana S. Campos, DPA
}

Bulacan State University, Philippines

\begin{abstract}
The Philippine economy's backbone has been referred to as micro, small and medium enterprises (MSMEs) and is also the subject of intense attention from many government institutions and corporate bodies. MSMEs are rightly seen as drivers of economic change and development. A leader, on the other hand, is someone who assumes a leadership position which, by setting a good example and being effective in what he does, inspires a team of followers by winning their confidence and respect. He actively empowers and directs them. This paper intends to examine the correlation between the characteristics of MSME owners or entrepreneurs regarded as leaders and employee productivity that may affect success. Data is collected through a survey from fifty (50) MSMEs of Bulacan, who were chosen by the purposive sampling method. Descriptive statistics and nonparametric tests (Mann-Whitney U test and the Kruskal-Wallis test) were conducted to examine sustainable productivity by demographic profile and leadership skills manifested by MSME owners. The results thereof indicate that leadership skills possessed by MSME entrepreneurs revealed a significant correlation when compared with employee productivity variables.
\end{abstract}

Keywords: Leadership skills; Entrepreneurial leadership; MSMEs; Employee productivity

This is an open access article under the CC-BY-NC license.

\section{INTRODUCTION}

The Philippines is recognized as one of Asia's fastest-growing economies. A critical driver of its growth is the micro, small and medium enterprises (MSMEs). They play an integral role in poverty alleviation through the creation of employment opportunities. As per the Department of Trade and Industry, the Philippine Statistics Authority provided a list of establishments registered as business enterprises operating in the country with a total of 1,000,506 in 2019. Of the total number, 995,745 are MSMEs, and 4,761 are large enterprises. These MSMEs produced a total of $5,510,760$ jobs or equivalent to $62.4 \%$ of the country's total employment. The largest share was generated by micro-enterprises (29.8 percent), followed closely by small enterprises (25.2 percent), while medium enterprises are further behind at 7.4 percent. Large enterprises created a total of 3,315,575 jobs, or 37.6 percent of the total employment of the country. In conjunction with the country's projected sustained economic development, further growth opportunities for MSMEs are as important as the increase in the number of Filipinos enquiring into entrepreneurship in the previous years. In addition, MSMEs account for twenty-five percent (25\%) of the total export income of the country. Sixty percent $(60 \%)$ of all exporters in the country are also projected to

Corresponding author

Josephine Diana S. Campos, DPA, strictlyaccred@gmail.com DOI: (to be assigned soon) 
belong to the MSME group. Through subcontracting agreements with large firms or as suppliers to exporting companies, MSMEs are able to contribute to exports.

The economic performance of MSMEs, as indicated by PIDS (2018), has been curbed as appeared by low degrees of productivity and worth added commitment to assembling. It could be contended that the principal driver of MSME/SME development lies not in outer help, however rather in the DNA inside the organization, in its degree of preparation and receptiveness to inner learning and the selection of innovative activities to adapt and win in a competitive situation. Thus, surmounting a host of challenges faced by MSMEs relative to sustainability is dependent on the skills of a leader. Unquestionably, the role of a leader in MSMEs is not quite the same as that of a just-propelled fire or a mature organization. New businesses need their leaders and managers to be in a steady state of motion and regularly executing an all-hands-on-deck approach every day, with being extraordinarily associated with the littlest everyday action, rather than a large organization, where the leader(s) frequently restrain themselves to graphing development, extension, long haul arranging and setting organization heading on a macro-level. It is possible to set leaders in MSMEs somewhere close to the two limits, wherein they have to supervise activities, both in all shapes and sizes. MSMEs are always developing, battling, and handling retention and employee engagement and productivity challenges, yet have an established sense of purpose, allencompassing qualities, and the capacity to improve that can be leveraged by the leader successfully.

Taking everything into account, likewise, MSME leadership is about providing a flexible and adaptable way of coping with work processes and methods in line with the development of businesses and employees. To better attest, modify or avoid approaches, a leader must know how and when to change or stop approaches, tools and processes that are expected to accomplish results. Substantially, this paper investigated the correlation between characteristics of MSME owners or entrepreneurs, such as the leadership skills they exude and employee productivity. According to Sejjaaka, Mindra and Nsereko (2015), owner-managers of businesses exhibited strong antecedents of resilience and innate will to succeed and adaptability to overcome constraints to sustainability, in particular, those concerned with productivity. They also exhibit leadership traits characterized by skills that may affect success. In view of the aforementioned substantiations, this study sought to identify the following: (a) demographic profile of MSME entrepreneurs; (b) level of leadership skills manifested by the MSME entrepreneurs that enable them to influence employee productivity in terms of leadership skills-conceptual, technical, interpersonal, emotional intelligence and social intelligence skills; (c) level of employee productivity in terms of work output by objectives, work accomplished, work unit effectiveness, and work quality; (d) level of significance on leadership skills of MSME entrepreneurs when clustered by demographic profile; (e) level of significance on employee productivity when grouped according to demographic profile; (f) level of significance between MSME entrepreneurs' leadership skills and employee productivity when the demographic profile is considered; and (g) relationship between leadership skills and employee productivity of MSMEs in Bulacan. The following research hypotheses are tested: (a) There is no significant relationship between leadership skills of entrepreneurs and employee productivity when the demographic profile is considered; (b) There is no relationship between leadership skills and employee productivity of MSME entrepreneurs in Bulacan. 
In précis, the results of this research could be considered as consequential because employees execute tasks at the entrepreneur's absolute prerogative. Notwithstanding the fact that leaders may also differ in terms of management, but their obligation to guide, embolden, and direct employees remain perpetual (Kumar et al., 2017). Leader-entrepreneurs are also beset with prolonged efforts to achieve overarching objectives relative to growth and sustainability, despite the fact that MSMEs have already made a substantial contribution to long-term economic development. However, the current economic order and situation, as well as trends relative to globalization, have changed the business environment, which also resulted in the need for specific types of leadership skills to improve work results. On this account, many researchers have pointed out that there is no single leadership skill that consistently aids in sustaining productivity and actualization of organizational goals. It is contingent on the circumstances and the employees themselves. Thus, it is vital to review and assess which sort of leadership skill is appropriate under which situations, as well as how leaders influence employee productivity in Philippine MSMEs.

\section{LITERATURE REVIEW}

Leadership for sustainable productivity is a generally new concept that constitutes a fundamentally extended comprehension of leadership that incorporates a broadened base of everyday leaders with varying backgrounds who take up power and engage in activities with others to have an economic effect in organizations and communities (Burns, 2015; Ferdig, 2007).

Craig (2019) delineated sustainable productivity as one that every company strives for. It requires constant growth and changes in procedures, a daily flow of new ideas and developments, and an imperturbable exuberance about the organization's future. The former also proposed ways to cultivate sustainable productivity in the course of doing business. Firstly, leaders or entrepreneurs must start with an example worth imitating. This is necessitated to maintain a culture of quality improvement and sustained productivity. Secondly, resort to mapping one's processes and data. For instance, to achieve sustainable production means to involve organizing data and using it in real-time for decision-making. Other times, this may mean that seeking more consistent productivity entails concentrating on internal processes and how workers operate efficiently in workflows that require teamwork. If a leader does not know what it looks like or how to measure it, productivity cannot be sustainable. Familiarity with SMART goals is of equal importance. For a start, instead of exhausting them with bigger, overarching ones, it means empowering workers to think of their jobs in smaller, actionable parts. Finally, a leader or entrepreneur must ensure that employees are not burned out. An entrepreneur has likely heard of flow, which is when an individual enters a profound concentration state in order to achieve an intense productivity surge.

A prerequisite to achieving sustainable productivity is a leader who possesses all the skills that effectuate productivity. The leader also influences individuals from the group by utilizing his/her initiative qualities so as to attain common objectives. In the same manner, Talat et al. (2018) assert that leaders help guide, direct and persuade their followers or workforce to achieve their personal and organizational objectives. In substantiation, Oluwadre (2019) corresponded that leaders are individuals responsible for guiding the influence of others. A leader can also be viewed as a person who controls the actions of others towards pre-determined objectives, otherwise known as organizational goals. Hence, guiding individuals to arrive at an objective requires diverse 
persuasion skills. To further attest, leadership and organizational productivity are intertwined, If sustainability becomes a central concern. The actualization of business imperatives depends, to some degree, on leadership. This categorically is confirmed and explicated by Bewany (2017). The latter also attested that an organization depends on leadership to guide them through unprecedented changes.

Theoretically, leaders who happen to be MSME owners and managers of sustainable businesses exhibit strong antecedents of resilience, social capital, resourcefulness, personal values and strategic flexibility (Sejjaaka, Mindra \& Nsereko, 2015). According to Young (2015), quality leadership matters. Effective leadership quality is influenced by preparation and development opportunities. Preparation entails a process towards being competent, innovative, motivated and target-oriented. It is fuelled and propelled by indefatigable energy and passion for ensuring that employees are qualified, informed and inspired to achieve success as well. In point of fact, Singh (2015) posited that leaders play a significant role in shaping the success and productivity of employees in organizations; leaders play an important role. The preceding inference was based on a survey of 413 employees of three private banks and three foreign banks (of US origin). The researcher found that transaction leadership played an important role in forecasting employee productivity in private banks, while transformation leadership was a predictor of employee productivity in the case of foreign banks. Furthermore, in the study of Shamaki (2015), the style of leadership significantly influenced productivity. Respondents were mostly educators who preferred the democratic style rather than the autocratic style.

On the other hand, Shahid and Azhar (2013) stressed the importance of a leader's attitude towards achieving his team's high level of productivity. The leadership style adopted by leaders of every organization is seen in the leader's character; that is, in the course of time, the leadership style rubs off on the attitude of the leader towards his followers. It is also important to remember that the act of seeing workers in the organization as a team would inevitably contribute to changes in employee productivity levels; this is because no gaps or loopholes will be tolerated, everyone will work visibly in synergy to ensure high-level customer loyalty that is productivity in its sense.

This is in agreement with Segun-Adeniran's (2015) claim that the productivity of every organization is significantly influenced by leadership because Leaders have the ability to make strategic decisions that will keep the company working properly or corrupt the organization's operations. In this light, the National Library Board (2010) unequivocally outlined several measures that should be taken to achieve a high degree of productivity, namely: (a) employee ownership and accountability; (b) goals and project definition; (c) management of employee satisfaction; (d) communication; and (e) recognition and incentives. Other than leadership skills, equally important and correlated to productivity is employee satisfaction. Edwards (2015) correlated satisfaction highly with productivity. As evidence of its interrelationship, the Harvard Business Review (2019) recently released an overview of different studies showing an average of 31 percent higher productivity and 37 percent higher revenue when workers are pleased or satisfied. Sgroi (2015) discoursed the findings of economists at the University of Warwick, which appertained to happiness that results in a 12 percent growth in productivity. Unhappy employees have also been revealed to be 10 percent less productive than content employees.

In attestation, Revesencio (2015) argued that there is a fairly clear opportunity for organizations. Research reveals that when a person is feeling positive, the brain functions much 
better. To boot, during those days, people tend to be more creative and effective at solving problems. Chehrazi (2016) pointed out that life is constantly moving towards being new, and productivity is considered a necessity. Increasing productivity in individuals could lead to the promotion of quality and quantity of services, reduction of costs, prevention of waste of resources, reduction of bureaucracy, the elevation of competition, enhancement of efficiency and creation of motivation and job satisfaction of employees. According to Hill (2019), the overall satisfaction of an employee with his work is the product of a variety of factors, and only one of them is financial compensation. Other than monetary need, the following are factors that affect employee satisfaction: (a) optimal working conditions, such as the provision of productivity tools -advanced information systems to help employees execute tasks; (b) opportunity for advancement, this is why many firms encourage employees to acquire more technical skills, contributing to the opportunity for promotion. But on the other hand, Landes (2012) made a clarification that if one employer decides to pay for the education of its employees, it makes an investment in those employees. In a certain capacity, the degree should help the employee "perform better". That would mean either driving more sales or reducing more expenses in some of these instances; (c) attributed to falling short of deadlines, the workload and stress level leads to tension between employees and supervisors and increases the workplace stress level. The organization functions in a crisis mode since leaders do not give employees enough time to efficiently execute their assigned tasks. In like manner, Ali and Farooqi (2014) found out in the results of their study that due to numerous problems such as work overload, coworker actions, etc., the stress in work becomes detrimental not to itself, but to the organization. By giving preparation, orientation, proper pay package, equal employment opportunities, this stress can be minimized. Karatepe (2013) also pointed out that work overload contributes to ineffective job results. In other words, Chadegani, Mohamed \& Iskandar (2015), and Ali and Farooqi (2014) initiate that when employees are subjected to more than they can undertake, the efficiency in their performance of tasks may begin to deteriorate; (d) respect from co-employees. Employees should have to be reminded about what actions are deemed unacceptable while communicating with subordinates. Ramjee (2019) argued that whenever an employee feels emotionally or socially detached at work and does not seem to fit into the culture of the company or merge with other peers, feelings of discontent can begin to emerge. This may affect productivity. Effective managers with idyllic yet effective leadership skills know their employees need appreciation and praise for their contributions and achievements. Employees will want their supervisor's door open for them to address any issues they have that impair their capacity to do their work productively. The preceding elaborations are in line with the previous study of Madhani (2018); in addition to minimizing employee turnover, the former disclosed rewards optimization also increases the efficiency of retained employees as it takes into account the needs of the employees, their territorial characteristics and the needs of the organization.

With reference to productivity, Butt, Waseem, Rafiq, Nawab and Khilji (2014), leaders are in a position to exercise tremendous pressure and power to increase the productivity and performance of employees and staff and are unlikely to be affected as they are resilient to this effect. Leaders may exude impactful skills to further boost employee productivity. One of these is technical skills. A classical yet theoretical delineation is that of Kantz (1974), like those that include processes, strategies and approaches that help leaders grasp a specific topic or any problem at hand. These attributes can provide leaders with reliable knowledge about organizational structures and 
employee characteristics. It is also worth noting that leaders with conceptual skills are comfortable talking about the ideas that shape an organization and the intricacies involved (Northouse, 2016). Additionally, leaders need conceptual skills to participate in the process of growth, organization and decision making. Leaders need to know the work and functionality of the organization and must possess these conceptual skills to achieve high productivity from employees. Furthermore, leaders also possess interpersonal skills, which also comprise of those abilities that help leaders to understand the competencies needed to organize and synchronize the actions and deeds for them and others. This is supported by the findings of Wolf (2018), which included the determination of relevant competencies that operations managers would need to effectively lead their employees. The results showed that among the identified competencies to be most important is the interpersonal skills and other than negotiation and persuasion skills.

From a scientific standpoint, emotional intelligence (EI) is the ability to accurately perceive your own and others' emotions; to comprehend the signals that emotions send about relationships; and to manage your own and others' emotions. It does not generally hold the characteristics that some common descriptions attribute to it (such as optimism, initiative, and self-confidence (Ovans, 2015). EI is focused on the degree to which feelings and causes are mutually put in a way such that feelings and emotions are used to help cognitive procedures and sensibly manage feelings (Haq, 2011). Leaders with a high degree of emotional intelligence are conscious and effective at controlling and communicating their emotions. They can read emotions in others correctly and know how to treat them to achieve desired goals. Advantageously, higher emotional intelligence leads to better relationships with others. Higher emotional intelligence leads to improved connections with others. Leaders can overcome challenges such as time management, crisis management, and sound decision making (Dean, 2018). Thus, leaders can easily understand the personalities and concerns of their employees with the aid of EI and are therefore in a position to solve the problems and improve the performance of EI.

The Social Intelligence (SI) of a leader also plays an essential part in coping with employees. It requires social perceptiveness, which enhances the willingness of leaders to consider the needs of the organization and the employees. SI, according to Rahim (2018) is the ability to be conscious of specific social situational situations; to deal effectively with contexts or challenges; to consider the concerns, attitudes and emotional states of others; and to communicate plainly and convincingly about what to say, when to say it and how to say it, and to create and sustain meaningful relationships with others.

Heretofore, productivity and sustainability are correlative terms. In the study of Eames \& Collins (2017), long term productivity and sustainability can both be realized only if enhanced management practices are established and enforced. ADEC Solutions (2018), also referred to as Sustainability Consultant for Business \& Industry, attested that a healthy and sustainable workplace correlates to happier employees and, as a result, increased employee productivity and fewer work-related illnesses, injuries and accidents. This, in turn, could mean greater profits and long-term sustainability for companies. There are long-term benefits of business sustainability. These lead not only to short-term results but rather to organizational resilience, which is known as the firm's capacity to sense and correct maladaptive tendencies and deal with unexpected situations positively. Because organizational resilience is a latent, path-dependent construct, through the long-term outcomes, including improved financial volatility, sales growth, and survival 
rates (De Ortiz \& Bansal, 2015); therefore, the performance of MSMEs is crucial for economic growth and social solidity through the development of the citizens of the country and the creation of a remarkable number of new jobs. Small-medium enterprises are also essential in the manufacturing of goods and delivery of services (Karanja et al., 2013). Amash (2012) added that small business as being crucial to the creation of economic wealth, nationally and locally. Hyz (2011) declared that in developed countries and emerging economies, SMEs are the main source of economic growth. Furthermore, Vargo and Seville (2011) stated that SMEs are highly instrumental for job creation, and, indeed, MSMEs are a major contributor to the economy. All points considered, leadership is necessary for organizational growth and success. When leadership results in positive efficacy of performance, which corresponds to employee productivity, it is considered determinative. The relationship between the five leadership skills, i.e. technical, conceptual, interpersonal, emotional intelligence and social intelligence and employee productivity, has not yet been clarified, so it is not conclusive which one is evident in Philippine MSMEs. This research becomes imperative since the relationship between skills and productivity will be identified.

\section{RESEARCH METHOD}

The importance of descriptive design in the research process cannot be overstated. The descriptive method was employed because of its suitability to the problem. As stated by Mccombes (2019), descriptive research may analyze one or more variables using a wide range of quantitative and qualitative methods. Bhat (2019) added that descriptive research is a research method that defines the features of the population or phenomenon that is being studied. Instead of the "why" of the research topic, this methodology focuses more on the "what" of the research subject. Three main purposes of descriptive studies can be explained as describing, explaining and validating research findings.

With regard to data collection, the researcher utilized an electronic/online survey questionnaire as the main instrument or primary source of data. Other information was gathered from secondary sources such as websites and research papers, and/or journals. The material gathered is qualitative, and the researcher must locate secondary data that is relevant to the research issue. Consequently, all of these supplementary materials, as well as the theories and concepts sections, are used in constructing the overview fragment. This data-gathering procedure will aid in conducting credible research. Correspondingly, data analysis is also a necessary component of the research method. The data acquired from various secondary sources were analyzed using SPSS as well as correlation. As a result, it is ensured that the research process is carried out in a reliable and valid manner.

As per sampling size and technique, for reasons of non-availability of the complete list of MSMEs, the purposive sampling approach was selected rather than random sampling. More specifically, in the province of Bulacan. Furthermore, a list of all existing MSMEs is needed for random sampling in the province of Bulacan. On this point, the only list of small and medium enterprises that could be provided appertain to those enterprises that are registered with the Department of Trade and Industry (DTI). The selected province of the study necessitates obtaining the required list from the following municipalities, namely, San Jose Del Monte Bulacan, Malolos, Bustos, Sta. Maria and Marilao. In spite of repeated follow-ups, it could not be made available. Moreover, even if made available, the list of MSMEs registered with the DTI does not cover the 
entire set of existing MSMEs as the registration is voluntary. The eventual purpose of selecting a sample is to make judgments about the population in terms of the specified characteristics on the basis of the sample characteristics. In addition, if the investigation is to study leadership skills relative to productivity and sustainability, in this case, the sample must be smaller in size and richer in data, and respondents have to be considerably cooperative - conditions that can scarcely be met by a random sample. In such a case, the researcher may have to decide on his sample in such a way that these prerequisites and conditions are realized. In selecting the respondents, purposive sampling was applied. The entrepreneurs of MSMEs in Bulacan were taken as respondents of the study. The total number of respondents are 50 MSME owners (selected MSMEs were taken from the municipalities of Bulacan, namely; San Jose Del Monte Bulacan, Malolos, Bustos, Sta. Maria and Marilao.

With reference to the statistical treatment of data, quantitative methods were employed to determine the following: (a) the profile of respondents in Bulacan; (b) leadership skills manifested by the MSME entrepreneurs relative to demographic profile; and (c) the relationship between leadership skills and sustainable productivity. Qualitative methods were utilized in the observation and interpretation of texts, including interviews and discussions. Kruskal Wallis test was applied in the study. Apart from Kruskal Wallis, Mann-Whitney U tests were conducted to examine sustainable productivity by demographic profile and leadership skills manifested by MSME owners. Lastly, the Pearson product-moment correlation coefficient (or Pearson correlation coefficient, for short) was employed to determine the strength of a linear association between two variables that were particularized in the statement of the problem.

\section{FINDINGS AND DISCUSSION}

The following are the major findings revealed based on the online questionnaire responses:

(a) There were $62 \%$ female and $38 \%$ male respondents who willfully participated in the conduct of the study. As for the age group, most respondents are in their mid-thirties, with 58 percent out of a 100. With regard to family size, the average family of an MSME entrepreneur consisted of 5 to 10 household members (50\%). With regard to annual income, 28 percent of respondents claimed that their earnings belong to the highest income bracket. In terms of the type of industry where employees are engaged, the majority of MSMEs in operation are in the food business (28\%). Concurrently, the type of employment preferred by most MSMEs was full-time employment or full-time supervision. Educational attainment of MSME entrepreneurs was generally higher in college or associate degree completion with $60.0 \%$ responses.

(b) The technical skills of MSME entrepreneurs were assessed. Respondents concurred that entrepreneurs' technical skill is proportionate to their effectiveness with the detailed aspects of work is somewhat true with 4.4. On the other hand, forecasting ability only garnered 2.6. Both of the aforementioned were interpreted as "occasionally true". In the aspect of conceptual skills of an entrepreneur as a leadership trait, respondents rated flexibility in making changes in the business with 3.4. Among the interpersonal skills of an entrepreneur, the indicator that seemed to be protruding is being respectful to one's opponent, otherwise known as competitors. The latter obtained 4.0 computed mean and verbally interpreted as "somewhat true". It was found out that entrepreneurs, according to respondents, were not that keen to find consensus in conflict situations 
with a 2.2 computed mean. Leaders, in general, also possess social intelligence skills. In the case of MSME entrepreneurs, respondents rated "listens closely to team members and incorporate ideas into the plan" with 4.4. However, "resolving conflicts with team members, customers and vendors" obtained the lowest score of 3.6.

(c) Respondents rated the initiative of the employee to devise tools to help the enterprise meet its goals with 3.6. Entrepreneurs expect their employees to accomplish their tasks. Relative to the aforementioned expectation, respondents rated the initiative of the employee to report with their supervisors and discuss progress as well as solutions with 4.0. Likewise, the indicator that specifies "employee spends fewer hours for non-work-related conversations or activities to that delay accomplishment of tasks" obtained the same. The lowest computed mean of 3.6 was assigned to "meeting the target number of products expected to be produced or services expected to be performed". Employees are also considered effective in the performance of their task if they are capable of taking criticisms in a constructive manner and applying these corrections afterwards. The previously mentioned characteristic of work unit effectiveness obtained the highest mean score of 4.0. Dismally, the indicator which specifies "errors and mistakes are handled appropriately so as not to affect the image of the business" got the lowest computed mean. As per work quality, respondents rated having fewer customer complaints with 3.0, being the lowest computed mean score.

(d) The exact test and the normal approximation provide similar results to indicators one to four, namely: technical, conceptual, interpersonal, and emotional intelligence. Conclusively, there is no real evidence that the leadership skills at diagnosis are different for males and females, even though the results or findings are borderline and the lack of statistical significance, in this case, may just be due to the very small sample. The exact test and normal approximation, as per age, yield identical results to all measures of leadership skills. Evidently, there is no substantial evidence that the leadership skills at diagnosis are different for three age groups, specifically: 30-39, 40-49, and 50 and above. Thus, it lacked significance. In terms of family size, all family size categories lacked significance when compared with leadership skills. However, when it comes to annual income, technical and social intelligence skills manifest significance when compared with annual income categories. By the same token, the analysis also revealed that technical and social intelligence skills were different between the kind of industries in which they are involved. As per leadership skills,

(e) Employee productivity, when compared to sex, more specifically work output by objectives and work unit effectiveness, were significant. As per age, all indicators of employee productivity turned out to be lacking in significance or not statistically significant, with respective p-values $>0.05$. With family size, work output by objectives and work unit effectiveness were significant with respective $p$-values $<0.05(\mathrm{p}=.016 ; \mathrm{p}=0.000)$. The annual income categories were also tested and compared with employee productivity indicators. However, work quality was found to be significant when compared between annual income categories. When comparing employee productivity between the types of industry, work unit effectiveness and work exhibited significance at respective $p$-values $\mathrm{p}=0.001$; and $\mathrm{p}=0.012$. The indicators of employee productivity were also compared with the highest level of education attained. All indicators lacked significance, except for work quality. 
(f) The leadership skills were also tested and compared with the demographic profile. All demographic characteristics, specifically: age, sex, family size, annual income, type of employment, type of industry, and the highest level of education, were found to be significantly different with pvalues not exceeding 0.05 .

(g) The magnitude of the correlation between the leadership skills and employee productivity as calculated by the correlation coefficient was of different $r$ values $(0.073-0.702)$. Interestingly, the technical, interpersonal, and social intelligence skills indicated $\mathrm{p}$ values less than 0.05. These skills possessed by MSME entrepreneurs manifested a significant correlation when compared with employee productivity variables (work output, work accomplished, work unit effectiveness and work quality).

Table 1. Relationship Between MSME Entrepreneurs' Leadership Traits and Employee Productivity

\begin{tabular}{|l|c|c|c|c|c|}
\hline Leadership Traits & $\begin{array}{c}\text { Correlation } \\
\text { Coefficient }\end{array}$ & Interpretation & p-value & Decision & Remarks \\
\hline Technical Skills & 0.644 & $\begin{array}{c}\text { Moderate } \\
\text { Positive } \\
\text { Correlation }\end{array}$ & 0.000 & Reject Ho & Significant \\
\hline Conceptual Skills & 0.221 & $\begin{array}{c}\text { Negligible } \\
\text { Correlation }\end{array}$ & 0.123 & Retain Ho & Not Significant \\
\hline $\begin{array}{l}\text { Interpersonal } \\
\text { Skills }\end{array}$ & 0.358 & $\begin{array}{c}\text { Low Positive } \\
\text { Correlation }\end{array}$ & 0.011 & Reject Ho & Significant \\
\hline $\begin{array}{l}\text { Emotional } \\
\text { Intelligence Skills }\end{array}$ & 0.073 & $\begin{array}{c}\text { Negligible } \\
\text { Correlation }\end{array}$ & 0.616 & Retain Ho & Not Significant \\
\hline $\begin{array}{l}\text { Social Intelligence } \\
\text { Skills }\end{array}$ & 0.702 & $\begin{array}{c}\text { High Positive } \\
\text { Correlation }\end{array}$ & 0.000 & Reject Ho & Significant \\
\hline
\end{tabular}

\section{Discussion}

Based on the aforementioned findings, the following points of discussion were derived:

Findings revealed that most respondents were female (62\%). Women are more likely to accommodate work and regard themselves as being flexible in finding ways to provide money for their families. Respondents are in their mid-thirties since building one's destiny and experience take time. Respondents also claimed that they are earning the most amount of money, which belonged to the highest income level. They also justified that the amount of earnings is dependent on the type of industry one engages himself in. Besides the income, respondents considered themselves full-time due to the number of hours they render for their respective businesses.

Respondents regarded technical skills as one important leadership trait. It stood amongst other skills. Entrepreneurs are also expected to forecast and react faster to market shifts to win deals. Technical skills are insubstantial if forecasting is not evident. Conceptual skills, on the other hand, enable entrepreneurs to comprehend the overall functioning of the business. Interpersonal skills of entrepreneurs, in general, were also found "somewhat true" since entrepreneurs were able to observe respect their opponents, otherwise known as "competitors". Entrepreneurs, however, were not that keen on finding consensus in conflict situations. Interpersonal skill is the most critical skill. Entrepreneurs regarded as leaders are presumed to listen with genuine interest so as to gain an understanding of every aspect of the business and its people. Entrepreneurs, in general, possess 21 
social intelligence skills. An entrepreneurial leadership trait is supposed to encourage entrepreneurial attitudes and behaviors in employees. However, the ability to resolve conflicts with team members, customers and vendors was not rated highly.

In a particular period of time, employee productivity was measured in terms of an employee's output. Much of the success of any given business depends on the productivity of its employees. The aforementioned is true and evidenced by the respondents' concurrence of work output indicators as "sometimes true" only if applicability is at a turning point. Entrepreneurs are also expectant of employee initiative to discuss progress and solutions to problems relative to daily operations. Performance-wise, employee-respondents gave the lowest rating to "meeting the target number of products expected to be produced or services expected to be performed". This is when the entrepreneur customarily ensures that they are working as effectively and efficiently as they can every day. Respondents also assigned the lowest computed mean for having fewer customers complaints and errors being handled appropriately.

All leadership skills, specifically: technical, conceptual, interpersonal, and emotional intelligence, did not exhibit any evidence of relationship with sex. Similarly, leadership skills were also compared to age and family size. Both did not manifest significance. However, when it comes to annual income, technical and social intelligence skills manifest significance when compared with annual income categories. In actual fact, specialized leadership skill is often equated to the amount of income earned. Likewise, the analysis also revealed that technical and social intelligence skills were different in the type of industries they are engaged in. What is more, performing any job requires the use of multiple skill sets.

With relevance to demographic profile and productivity, sex was found significant when compared with work output by objectives. Many explanations can be attributed to the aforementioned, such as differences in skills and preferences; and competition and time constraints. As per work unit effectiveness, there is a significant relationship when compared to sex. This is due to the type of task assigned to both sexes. There is a statistically significant relationship between work output by objectives and family size. A married respondent with a family size of 5 to 10 members explained that she does not want to work late or too many on the weekend, so when she's in the store supervising and managing, she gets everything done. She also added, her productivity at work serves as motivation. It allows her to spend quality time with family at home. The same can be applied to work unit effectiveness and family size. Both are statistically significant to one another. As per the type of industry and work quality, both were significantly related. There are industries that overhaul themselves and keep apace to cope up with the competitive climate. Work quality is one example of doing right the first time, and employees capable of meeting such earn an income that matches their capabilities.

The leadership skills were also tested and compared with the demographic profile. Both were found to be significantly different to one another, considering their computed $p$-values. This clearly meant that leader-entrepreneurs have a common set of demographical characteristics that support their ability to mobilize follower-employees toward a shared vision. Leadership skills possessed by MSME entrepreneurs such as technical, interpersonal, and social intelligence skills manifested a significant correlation when compared with employee productivity variables (work output, work accomplished, work unit effectiveness and work quality). Incontestably, raising and sustaining 
employee productivity is an essential element of a business operation. Thus, a leader plays a vital role in ensuring work performance levels with regard to increased output and high quality.

\section{CONCLUSION}

The aim of this paper was to examine the characteristics of MSME owners or entrepreneurs and their relationship to employee productivity. The research has been conducted in Bulacan. A review was done analysis leadership theories, models and past literature carried out by other researchers to adopt the different determinants that impact the realization of sustainable employee productivity. A conceptual framework was established with an independent variable which consists of leadership skills, and a dependent variable, which comprises sustainable employee productivity and its aspects. This paper utilized the descriptive method of research. Using the 5-point Likert Scale, a set of questionnaires with structured questions was generated and measured.

In view of the above, the researcher recommends the following:

Most MSMEs are controlled by females due to their flexibility and motivation to provide money for their families. This also is an indication that MSMEs are characterized by the predominant presence of females. For this reason, gender-gap should be abrogated since not all MSMEs are women-owned and women-led. Personal characteristics should not be considered a default option for employment or running a business on the grounds of having diverse cultural and socio-economic backgrounds.

According to the results previously described, forecasting ability obtained the lowest computed mean. MSMEs need a direction. Forging ahead while lacking clearly defined goals has the potential for dire negative consequences. Goals and direction are conceivably most important when it comes to the lifeblood of a business which is money. Entrepreneurs should be able to map future uncertainties by looking at possible changes or possibilities. Conceptual skills should not be limited to merely a comprehension of the overall functioning of the business. It is highly recommended for entrepreneurs to work on developing their analytical and cognitive abilities. They should engage themselves to enroll on short courses other than seminars/ training on business management and network with people from within and outside industry to further hone conceptual skills. With relevance to interpersonal skills, a healthy climate for work would necessitate entrepreneurs to practice active listening skills during all conversations with employees, appreciate employees through recognition of their contribution to the smooth operation of the business (including conflict resolution), and promote a healthy climate for work. Entrepreneurs should realize that conflict resolution is a daily occurrence at any business operation. A feasible recommendation is to employ conflict resolution strategies (avoidance, competition, accommodation, compromise, and collaboration). Work quality, work unit effectiveness and work output were only evaluated as "sometimes true". An entrepreneur should certainly implement strategies to improve the work quality and output of employees. These may include but are not limited to: (a) elimination of processes that are of little or no value; (b) invest in employee orientation and training; (c) establish the appropriate level of sustainable productivity and quality goals, and (d) implement changes. Work unit effectiveness will likely be commensurate with the desired level of productivity once all these are put into practice. 
Based on the results obtained, the social intelligence skills of an entrepreneur is significantly related to sex. The "female" entrepreneurs scored higher in social intelligence skills. In this case, it is highly recommended for male entrepreneurs to spend time with their employees and invest in developing better working relationships with them. With reference to annual income, technical, interpersonal and social intelligence skills manifest significance when compared with annual income categories. Acquisition of soft skills is not limited to engineers, mathematicians and IT experts. An entrepreneur should be well-versed in soft skills/technical skills due to the rise of technology that makes it relevant to nearly every industry. Similarly, the analysis also revealed that technical and social intelligence skills were different in the type of industries they are engaged in. An entrepreneur should master bought interpersonal and social intelligence skills, especially those referents to verbal and nonverbal communication. On the other hand, relationship management (which includes the extent of influence, coaching/mentoring, conflict management, inspirational leadership and teamwork) should be the central point of interpersonal and social intelligence skills development.

With reference to productivity, sex was found significant when compared with work output by objectives and work unit effectiveness. Gender gaps should no longer be an issue since there is increasing jobs brought about by the growth of MSMEs.

In addition, implementation of strategies on work output and work unit effectiveness (i.e., identification of priorities and goals, time management/productivity through activity logsheet, continuous training \& development) should be the main focus of entrepreneurs. There is also a statistically significant relationship between work output by objectives, work unit effectiveness and family size. As per the type of industry, work unit effectiveness and work quality were significantly related to the industry. In any given industry, policies have to be in place to ensure quality and high productivity standards are met. Policy implementation alone may not be sufficient if the employee is not in an environment where productivity is promoted.

Work quality is also significantly related to income and educational attainment. Entrepreneurs should provide employees with a reasonable income coupled with benefits. The fact is that higher wages tend to promote a high-output culture. As for educational attainment and its relation to work quality, the results served as evidence that educated employees may perform more effectively in meeting work quality standards. With a reasonable income that commensurate educational attainment, employees are driven to perform well and demonstrate the desire to complete tasks. Thus, it is recommended for entrepreneurs to hire educated employees to boost productivity. Leadership skills and demographic profiles were found to be significantly different to one another, considering their computed p-values. In this regard, entrepreneurs are highly encouraged to invest in personal, professional growth and development. They may also set aside an amount dedicated for the continuous training and growth of employees. Leadership skills possessed by MSME entrepreneurs (i.e., technical, interpersonal and social intelligence skills) manifested a significant correlation when compared with employee productivity variables. An entrepreneur's leadership skills, in general, would further empower employees by developing their capabilities according to some measure of authority and influence. An entrepreneur may also apply a combination of leadership skills to ignite employee's potential and perform maximally towards sustainable productivity of MSMEs. This, in turn, will help sustain productivity vis-a-vis work unit effectiveness, work output by objectives, work accomplished and work quality. 


\section{REFERENCES}

Ali, S., \& Farooqi, Y. A. (2014). Effect of work overload on job satisfaction, effect of job satisfaction on employee performance and employee engagement (a case of public sector University of Gujranwala Division). International Journal of Multidisciplinary Sciences and Engineering, 5(8), 23-30.

Amash, R. (2012). The survival of small businesses in the absence supportive political and economic system. The Journal of American Academy of Business, 17, 186-191. Retrieved from http://www.jaabc.com

Bhat, A. (2019). Descriptive research: definition, characteristics, methods, examples and advantages. https://www.questionpro.com/blog/descriptive-research/

Bewany, S. (2017, April 1). The Impact of Leadership \& Culture on Productivity. Executive Development Associates. Retrieved from https://www.executivedevelopment.com/the-impact-ofleadership-culture-on-productivity/

Burns, H., Vaught, H., \& Bauman, C. (2015). Leadership for sustainability: Theoretical foundations and pedagogical practices that foster change. International Journal of Leadership Studies, 9(1), 88-100.

Butt, F. S., Waseem, M., Ra+fiq, T., Nawab, S., \& Khilji, B. A. (2014). The impact of leadership on the productivity of employees: An evidence from Pakistan. Research Journal of Applied Sciences, Engineering and Technology, 7(24), 5221-5226.

Chadegani, A. A., Mohamed, Z. M., \& Iskandar, T. M. (2015). The Influence of Individual Characteristics on Auditors' Intention to Report Errors. Journal of Economics, Business and Management, 3(7), 710-714. https://doi.org/10.7763/joebm.2015.v3.271

Chehrazi, K. A., \& Shafizadeh, R. (2016). The relationship of empowerment and job satisfaction with productivity of employees of education system in Ahwaz. International Journal of Learning \& Development, 6(1), 11-24.

Craig, W. (2019, May 14). 5 Ways For Boosting Sustainable Productivity In Your Workplace. Forbes. $\quad$ https://www.forbes.com/sites/williamcraig/2019/05/14/5-ways-for-boostingsustainable-productivity-in-your-workplace/?sh=18a611576844

Dean, J. (2018, July 26). Five signs of high emotional intelligence. https://www.spring.org.uk/2018/07/emotional-intelligence.php

Department of Trade and Industry. (2019). 2019 MSME Statistics. Retrieved January 31, 2021, from https://www.dti.gov.ph/resources/msme-statistics/

Editorial Board. (2010). Library \& Information Science Research, 32(2), IFC. https://doi.org/10.1016/s0740-8188(10)00012-5

Eames, H., \& Collins, R. (2017). Grains Best Management Practices: delivering productivity and sustainability outcomes for the central Queensland grains industry. Rural Extension and Innovation Systems Journal, 13(2), 121.

IN FOCUS: The Fourth Industrial Revolution: What It Means for Philippine Firms. (2018, September 17). https://pidswebs.pids.gov.ph/CDN/INFOCUS/pidsupdates70.html

Edwards, S. (2015, October 29). Examining the Relationship between workplace satisfaction and productivity. https://www.inc.com/samuel-edwards/examining-the-relationship-betweenworkplace-satisfaction-and-productivity.html 
Ferdig, M. A. (2007). Sustainability Leadership: Co-creating a Sustainable Future. Journal of Change Management, 7(1), 25-35. https://doi.org/10.1080/14697010701233809

Happier employees $=$ greater success. (2019, August 21). Canadian HR Reporter. https://www.hrreporter.com/focus-areas/wellness-mental-health/happier-employees-greatersuccess $/ 315498$

Haq, S. (2011). Ethics and leadership skills in the public service. Procedia-Social and Behavioral Sciences, 15, 2792-2796.

Hill, B. (2019, March 7). Factors Affecting Job Satisfaction. Hearst Newspapers, LLC. https://smallbusiness.chron.com/factors-affecting-job-satisfaction-20114.html

Hyz, A. B. (2011). Small and medium enterprises (SMEs) in Greece - Barriers in access to banking services. International Journal of Business and Social Science, 2, 161-165. doi.10.3402/qhw.v9.23606

Karatepe, O. M. (2013). High-performance work practices, work social support and their effects on job embeddedness and turnover intentions. International Journal of Contemporary Hospitality Management, 25(6), 903-921. https://doi.org/10.1108/ijchm-06-2012-0097

Karanja, T., Muturi, P., Mukabi, M., Kabata, D., Wahome, S., \& Kayogo, M. (2013). Small business management. International Journal of Business and Social Science, 4, 113-142. DOI: $10.30845 /$ ijbss.

Katz, R.L. (1974 September). Skill of an effective administrator. Leadership Development Magazine. Harvard Business Review.

Kumar, Rathan \& Bhatti, Hassan Shakeel. (2020). The Impact of Leadership on Employee Performance in SMEs of Australia. 217-226.

Landes, L. (2012). Tuition reimbursement: A benefit for some employees and employers. Forbes. http://www. Forbes. com/sites/moneybuilder/2012/07/20/tuition-reimbursement-abenefit-for-some-employees-and-employers.

Madhani, P. (2018). Enhancing Return on Salesforce Investment: Reallocating Incentives and Training Resources with Intrinsic Valuation Approach. ICFAI Business School. https://doi.org/10.1177/0886368718790294

McCombes, S. (2019). Sescriptive research. https://www.scribbr.com/methodology/descriptive-research/

Northouse, G. (2018). Leadership: Theory and practice. Sage publications.

Ortiz-De-Mandojana, N. \& Bansal, P. (2016, August 1). The long-term benefits of organizational resilience through sustainable business practices. Wiley Online Library. https://onlinelibrary.wiley.com/doi/abs/10.1002/smj.2410

Oluwadare Oreofe. P., Ola-Olorun, O. J., \& Oluwale, B. A. (2019). Assessment of Total Quality Management Adoption Level in Pharmaceutical Manufacturing Companies in Southwestern Nigeria. In International Journal of Engineering Research in Africa (Vol. 43, pp. 168-177). Trans Tech Publications Ltd.

Ovans, A. (2015, April 28). How Emotional Intelligence Became a Key Leadership Skill. Harvard Business School Publishing. https://hbr.org/2015/04/how-emotional-intelligencebecame-a-key-leadership-skill

Rahim, M.A. (2018), "Social intelligence”, Management: Theory, Research, and Practice, 3rd ed., Cognella Academic, San Diego, CA, pp. 117-228. 
Ramjee, G., Sartorius, B., Morris, N., Wand, H., Reddy, T., Yssel, J. D., \& Tanser, F. (2019, June 7). A decade of sustained geographic spread of HIV infections among women in Durban, South Africa. BMC Infectious Diseases. https://bmcinfectdis.biomedcentral.com/articles/10.1186/s12879-019-4080-6

Revesencio, J. (2019, July 22). Why Happy Employees Are 12\% More Productive. Fast Company \& Inc. https://www.fastcompany.com/3048751/happy-employees-are-12-moreproductive-at-work.

Segun-Adeniran, C. D. (2015). Leadership Styles and Job Productivity of University Library Staff: Interrogating the Nexus. Library Philosophy and Practice (e-journal). 1269. http://digitalcommons.unl.edu/libphilprac/1269

Sejjaaka, S., Mindra, R., \& Nsereko, I. (2015). Leadership traits and business sustainability in Ugandan SMEs: A qualitative analysis. International Journal Of Management Science And Business Administration. DOI:10.18775/ijmsba.1849-5664-5419.2014.16.1004

Sgroi, D. (2015). Happiness and productivity: Understanding the happy-productive worker. SMF-CAGE Global Perspectives Series, 2-20.

Shahid, A., \& Azhar, S. M. (2013). Gaining employee commitment: Linking to organizational effectiveness. Journal of management research, 5(1), 250.

Shamaki, E. B. (2015). Influence of Leadership Style on Teacher's Job Productivity in Public Secondary Schools in Taraba State, Nigeria. Journal of Education and Practice, 6(10), 200-203.

Singh, K. (2015). Leadership Style and Employee Productivity: A Case Study of Indian Banking Organizations. Journal of Knowledge Globalization, 8(2).

Solutions, A. E. (2015, June 16). Building a Sustainable Workplace. ADEC ESG Solutions. https://www.esg.adec-innovations.com/resources/newsletters/building-a-sustainableworkplace/building-a-sustainable-workplace/

Talat, M., Haider, K., Shahzadi, S., Muneer, R., Afzal, F., \& Ali, W. (2018). Leadership skills development through effective teaching and co-curricular activities at college level. WALIA Journal 34(1).

Vargo, John \& Seville, Erica. (2011). Crisis strategic planning for SMEs: Finding the silver lining. International Journal of Production Research. $49.4619-5635$. 10.1080/00207543.2011.563902.

Wolf, S. J. (2018, December 19). OPUS 4 | Competencies for SCOM Leaders at Times of the Digital Transformation: A Critical Analysis. Https://Opus4.Kobv.de/Opus4Hwr/Frontdoor/Index/Index/Searchtype/All/Start/46/Rows/50/Yearfq/2018/DocId/1273. https://opus4.kobv.de/opus4hwr/frontdoor/index/index/searchtype/all/start/46/rows/50/yearfq/2018/docId/1273

Young, M (2015) Effective leadership preparation: we know what it looks like and what it can do. Journal of Research on Leadership Education 10(1): 3-10. 